\title{
Mesoporous carbon-containing voltammetric biosensor for determination of tyramine in food products
}

\author{
Jolanta Kochana $^{1} \cdot$ Karolina Wapiennik $^{1}$ - Pawel Knihnicki ${ }^{1} \cdot$ Aleksandra Pollap $^{1}$ • \\ Paula Janus $^{1}$ - Marcin Oszajca ${ }^{1}$ - Piotr Kuśtrowski ${ }^{1}$
}

Received: 22 February 2016/Revised: 20 April 2016/Accepted: 29 April 2016/Published online: 21 May 2016

(C) The Author(s) 2016. This article is published with open access at Springerlink.com

\begin{abstract}
A voltammetric biosensor based on tyrosinase (TYR) was developed for determination of tyramine. Carbon material (multi-walled carbon nanotubes or mesoporous carbon CMK-3-type), polycationic polymer-i.e., poly(diallyldimethylammonium chloride) (PDDA), and Nafion were incorporated into titania dioxide sol $\left(\mathrm{TiO}_{2}\right)$ to create an immobilization matrix. The features of the formed matrix were studied by scanning electron microscopy (SEM) and cyclic voltammetry $(\mathrm{CV})$. The analytical performance of the developed biosensor was evaluated with respect to linear range, sensitivity, limit of detection, long-term stability, repeatability, and reproducibility. The biosensor exhibited electrocatalytic activity toward tyramine oxidation within a linear range from 6 to $130 \mu \mathrm{M}$, high sensitivity of $486 \mu \mathrm{A} \mathrm{mM}^{-1} \mathrm{~cm}^{-2}$, and limit of detection of $1.5 \mu \mathrm{M}$. The apparent Michaelis-Menten constant was calculated to be $66.0 \mu \mathrm{M}$ indicating a high biological affinity of the developed biosensor for tyramine. Furthermore, its usefulness in determination of tyramine in food product samples was also verified.
\end{abstract}

Keywords Biosensor $\cdot$ Tyramine $\cdot$ Food $\cdot$ Mesoporous carbon $\cdot$ Tyrosinase $\cdot$ Voltammetry

Electronic supplementary material The online version of this article (doi:10.1007/s00216-016-9612-y) contains supplementary material, which is available to authorized users.

Jolanta Kochana

kochana@chemia.uj.edu.pl

1 Faculty of Chemistry, Jagiellonian University, Ingardena 3, Krakow, Poland

\section{Introduction}

Tyramine ( $p$-hydroxyphenylethylamine), being a decarboxylation product of tyrosine, belongs to the group of biogenic amines [1]. This compound can be found in many food products (e.g., chocolate, wine, beer, cheese, beans, banana peel, ketchup, fish) and can be considered as their quality indicator, because the concentration of tyramine increases in perishable products $[2,3]$. Consumption of a large amount of tyraminecontaining food has a toxic effect on health producing symptoms such as flush, rash, vomiting, palpitation, tachycardia, and hypertonia [4]. Furthermore, it can lead to a dangerous blood pressure increase, accompanied by an attack of strong migraine headaches [5-7]. For these reasons, the development of sensitive, selective, and inexpensive methods for the determination of tyramine in food products is really an important issue.

There are some known methods for the determination of tyramine in various types of food. Most commonly, chromatographic methods for quantification of tyramine and other biogenic amines were reported, exemplary high-performance liquid chromatography [7-9], hydrophilic interaction liquid chromatography with tandem mass spectrometry (HILICMS/MS) [10], and ultra-performance convergence chromatography [11]. Moreover, capillary electrophoresis-tandem mass spectrometry [12] and capillary electrophoresis coupled with electrochemiluminescence [13] were tested. Nevertheless, most of them require complicated sample preparation, and they are expensive and usually time-consuming. Electrochemical (bio)sensors turned out to be a favorable alternative for the quantification of tyramine because of their simplicity, selectivity, and rapidity. Additionally, they do not require time-consuming sample pretreatment and expensive instrumentation. Recently, few types of electrochemical biosensors for the determination of tyramine have been described 
in the literature, including those using as an enzyme pea seedling amine oxidase $[4,14]$ or black gram tyramine oxidase $[2$, 15]. Electrochemical biosensing of tyramine based on tyrosinase was reported only twice. Apetrei at al. developed a biosensor with tyrosinase immobilized in phosphate-doped polypyrrole film [16] and produced the screen-printed electrode with enzyme entrapped in a carboxyl-functionalized singlewalled carbon nanotube composite [17].

Besides carbon nanotubes [18], graphene [19], and fullerenes [20], ordered mesoporous carbons (OMC) are often tested as components of novel biosensors. Among OMC, the most frequent CMK-3 and CMK-1 are employed for biosensor matrix preparation. The CMK-n-type replicas have gained the interest of scientists since the end of the 1990s [21, 22]. The good electronic conductivity, highly defined pore size distribution, high specific surface area, large pore volume, and enhanced mechanical stability cause them to be useful in catalysis, adsorption, and electrochemical applications, like a construction of chemical as well as biochemical sensors. For example, the CMK-3-type replica is characterized by the hexagonal arrangement of carbon nanorods with the specific surface area in the range of $900-1500 \mathrm{~m}^{2} \mathrm{~g}^{-1}$, total pore volumes of $1.1-1.7 \mathrm{~cm}^{3} \mathrm{~g}^{-1}$, and pore sizes ranging between 3.3 and $5.0 \mathrm{~nm}$ [23]. The widespread use of mesoporous carbon materials is noted in construction of amperometric, potentiometric, and voltammetric chemical sensors dedicated to the determination of metals [24], dopamine [25], glucose [26], hydrogen peroxide [27], NADH [28], explosive materials (TNT) [29], uric acid [30], and others. CMK-3 was also successfully used in preparation of a $(\mathrm{GCE} /$ \{chitosan/hemoglobin-CMK$3\}_{6}$ ) multilayer film-modified biosensor for hydrogen peroxide determination [31]. Furthermore, a functionalized CMK-3, synthesized using SBA-15 as the template and sucrose as the carbon source, has been found to be practical in the determination of toxic ractopamine in pork [32]. Direct electroanalysis of double-stranded DNA after accumulation and preconcentration on OMC-modified GCE-film electrode was presented by Wang et al. [33].

In this work, we present a voltammetric tyrosinase-based biosensor for the determination of tyramine. Tyrosinase (TYR) catalyzes oxidation of tyramine to corresponding $o$ quinone, which, being reduced at the electrode surface, generates current corresponding to the tyramine concentration (Scheme S1; see Supplementary Information). For the entrapment of enzyme titania sol-gel $\left(\mathrm{TiO}_{2}\right)$, modified with a carbon material, polycationic polymer poly(diallyldimethylammonium chloride) (PDDA) and Nafion were employed. Two different carbon materials were compared as the matrix components: multi-walled carbon nanotubes (MWCNT) and CMK-3-type mesoporous carbon. Our earlier research led to fabrication of a $\mathrm{TYR} / \mathrm{TiO}_{2} / \mathrm{MWCNT} / \mathrm{PDDA} /$ Nafion biosensor that exhibited good analytical characteristics, particularly in terms of sensitivity [34]. CMK-3 was taken into account as the biosensor matrix component due to its promising features related to the mesoporous structure. To characterize the properties of selected immobilized composites, scanning electron microscopy (SEM) and cyclic voltammetry (CV) were applied. The resulting biosensor was evaluated in terms of analytical parameters such as linear range, sensitivity, limit of detection, longterm stability as well as repeatability and reproducibility. Functioning of the proposed biosensor was checked in determination of tyramine in food samples (Camembert cheese, sauerkraut, and banana) with satisfactory results.

\section{Experimental}

\section{Chemicals and materials}

Tyramine (99 \%), glutathione (99\%), phenylalanine (98\%), titanium(IV) isopropoxide, tyrosinase from mushroom (EC1.14.18.1; $5771 \mathrm{U} \mathrm{mg}^{-1}$ ), vanillic acid, gallic acid, and poly(diallyldimethylammonium chloride) PDDA (average $\mathrm{Mw}<100,000,35 \mathrm{wt} \%$ in $\mathrm{H}_{2} \mathrm{O}$ ) were purchased from Sigma-Aldrich (USA); tryptophan (98.5-101 \%) and catechol were from Merck (Germany) and caffeic acid was from KochLight Laboratories; $\mathrm{HCl}(35 \%)$, ethanol (96 \%), 2-propanol, and L-(+)-ascorbic acid were obtained from Avantor Performance Materials Poland S.A. (Poland); $\mathrm{HNO}_{3}(65 \%)$, $\mathrm{NH}_{3}$ (aq) (25\%), and acetone were purchased from LACHNER (Czech Republic); $0.3 \mathrm{~mm}$ alumina powder was from Buehler Micropolish (USA); Nafion (5\% $(w / v)$ solution in mixture of low aliphatic alcohol and water) was obtained from Fluka. Furfuryl alcohol (98 \%, Aldrich), hydrochloric acid (33\%, Polish Chemical Reagents), and iron(III) nitrate nonahydrate (Polish Chemical Reagents) were used for CMK3 synthesis without any further purification. Phosphate buffer solutions (PBS) of pH 6.0 and 7.0, in a concentration of $0.1 \mathrm{M}$, were prepared by mixing appropriate volumes of $\mathrm{KH}_{2} \mathrm{PO}_{4}$ and $\mathrm{Na}_{2} \mathrm{HPO}_{4}$ solutions. Tyrosinase $(0.048 \mathrm{mg} / 10 \mu \mathrm{L})$ and tyramine solution were prepared in $0.1 \mathrm{M}$ phosphate buffer solution, $\mathrm{pH}$ 7. All chemicals were analytical-grade reagents. Milli-Q water was used throughout.

\section{Preparation of CMK-3}

Two different carbon materials were used in the preparation of biosensors: (i) commercially available multi-walled carbon nanotubes (MWCNT, Aldrich) and (ii) CMK-3-type carbon replica synthesized by the hard templating method using SBA-15 mesoporous silica (the complete synthesis protocol and characterization of SBA-15 are described in [35]). For the synthesis of CMK-3 material, $3.0 \mathrm{~g}$ of SBA- 15 was introduced 
into $94.0 \mathrm{~g}$ of distilled water containing $6.0 \mathrm{~g}$ of furfuryl alcohol (FA). Subsequently, hydrochloric acid was added at the $\mathrm{HCl} / \mathrm{FA}$ molar ratio of $6: 1$ and the slurry was heated up to $100{ }^{\circ} \mathrm{C}$. This temperature was kept for the next $6 \mathrm{~h}$ under vigorous stirring to ensure complete polycondensation resulting in precipitation of poly(furfuryl alcohol) (PFA) in the pore system of SBA-15. After that time, the obtained brown solid was filtered, washed with distilled water, and dried at room temperature overnight. Then, the PFA/SBA-15 composite was impregnated with an aqueous solution of iron(III) nitrate by the incipient wetness technique. The amount of introduced $\mathrm{Fe}^{3+}$ cations was selected to achieve the Fe concentration of $2 \mathrm{wt} \%$ in the PFA/SBA- 15 composite. After drying at $40{ }^{\circ} \mathrm{C}$, the material was calcined under inert atmosphere $\left(\mathrm{N}_{2}, 40 \mathrm{~mL} \mathrm{~min}^{-1}\right)$ at $850^{\circ} \mathrm{C}$ with a heating rate of $1{ }^{\circ} \mathrm{C} \min ^{-1}$ and an isothermal period of $4 \mathrm{~h}$. Finally, the silica template was removed by treatment with $5 \%$ hydrofluoric acid solution.

\section{Preparation of biosensor}

The first step of biosensor fabrication was cleaning of a graphite electrode surface by polishing with the use of alumina powder suspension and activating by sonication in different media. The titania sol was synthesized by acid hydrolysis and further polycondensation of titanium(IV) isopropoxide. The detailed procedures of these processes were reported in [36]. For the preparation of the matrix composite, the carbon material (MWCNT or CMK-3) was weighted (the mass depended on the number of produced biosensors) and mixed with a tyrosinase solution. Then, the mixture of titania sol and PDDA solution was added to the CMK-3/TYR (or MWCNT/TYR) suspension and shaken on the vortex. Finally, Nafion was gradually added and the mixture was shaken after each portion. The resulting composite was sonicated in an ultrasonic bath for $5 \mathrm{~min}$.

To prepare the biosensor, two $10-\mu \mathrm{L}$ portions of matrix composite were deposited on the previously prepared surface of graphite electrode and dried after each portion for ca. $10 \mathrm{~min}$. Then, the electrodes were left to dry above a saturated disodium phosphate solution at $4{ }^{\circ} \mathrm{C}$ for $20 \mathrm{~h}$. The biosensors were stored at $4{ }^{\circ} \mathrm{C}$ in $0.1 \mathrm{M}$ PBS (pH 6). Preparation of the biosensor is schematically presented in Scheme 1 .

Twenty microliters of matrix layer deposited on the electrode surface contained (per electrode) $0.041 \mathrm{mg} \mathrm{CMK}-3$, $0.039 \mathrm{mg}$ TYR, $1 \mu \mathrm{L}$ PDDA, and $5.7 \mu \mathrm{L}$ Nafion.

\section{Experimental setup}

The measurement technique was cyclic voltammetry conducted with the use of an M161 electrochemical analyzer (mtmanko, Poland) in a thermostatic cabinet (ST1, Pol-Eko Aparatura, Poland). All measurements were carried out in $0.1 \mathrm{M}$ phosphate buffer solution (PBS, pH 6) as supporting electrolyte. The conventional three-electrode system was employed with the carbon material-modified bioelectrode as the working electrode, the saturated silver/silver chloride reference electrode, and the platinum wire auxiliary electrode (mtm-anko, Poland). The experiments were conducted at a

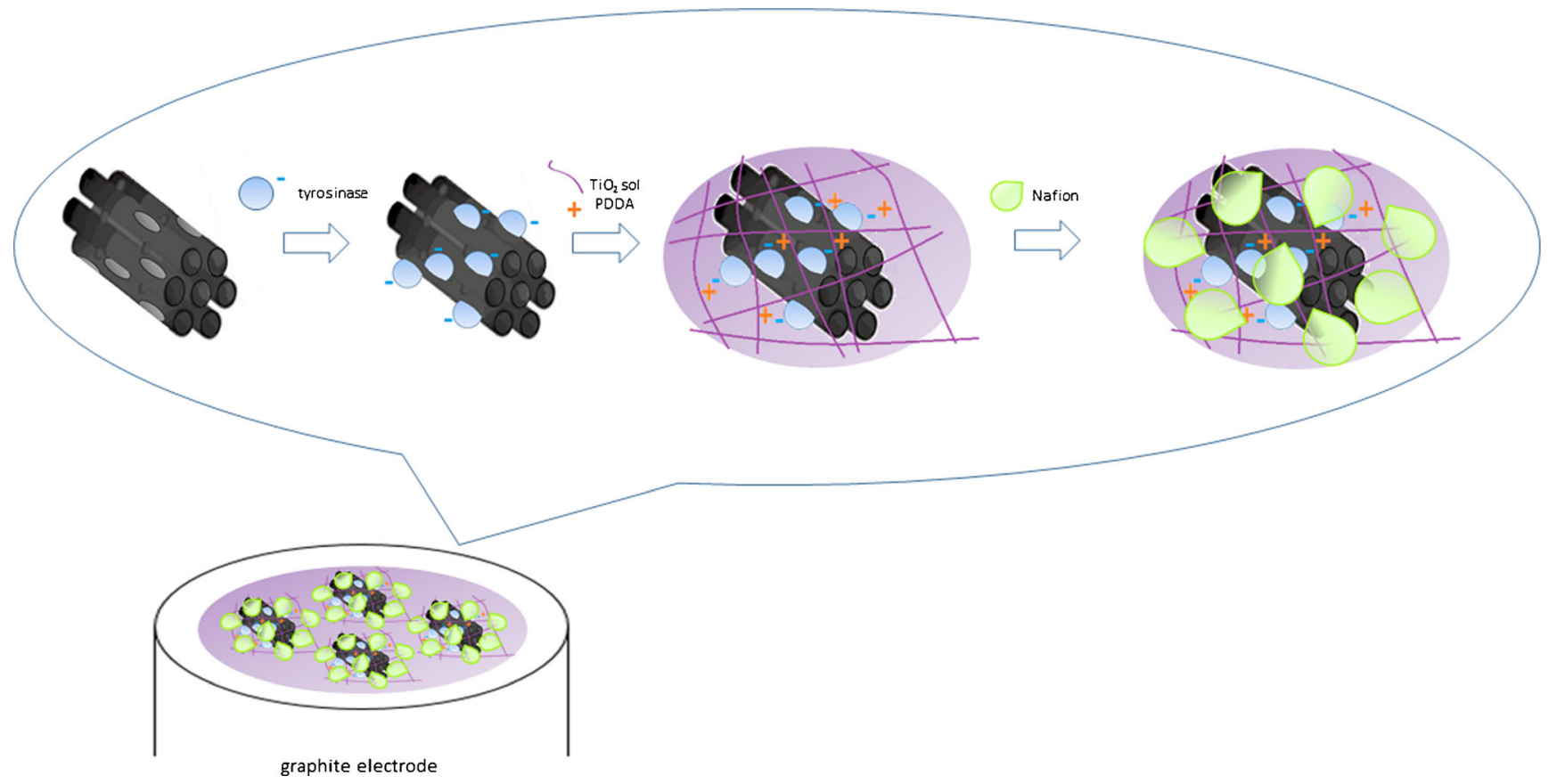

Scheme 1 Schematic illustration of $\mathrm{TYR} / \mathrm{TiO}_{2} / \mathrm{CMK}-3 / \mathrm{PDDA} /$ Nafion biosensor preparation 
temperature of $25^{\circ} \mathrm{C}$, in a potential range from -0.5 to $0.8 \mathrm{~V}$ and at a scan range of $62.5 \mathrm{mV} \mathrm{s}^{-1}$.

A vortex mixer (Labnet, USA) and a Sonic 3 Ultrasonic bath (Polsonic, Poland) were used to prepare homogenous matrix composites and extracts of food products (banana, sauerkraut, and Camembert cheese). A homogenizer (WITKO, Poland) and centrifuge (MPW Med. Instruments, Poland) were used for preparation of food samples. The $\mathrm{pH}$ of phosphate buffer solutions was measured with the use of a combined glass electrode, ERH-11 (HYDROMED, Poland), and a CP-501 pH-meter (Elmetron, Poland).

The structure of the carbon materials was examined by Xray powder diffraction (XRD) using a Bruker D2 Phaser instrument with a LYNXEYE detector. The diffraction patterns were collected using $\mathrm{Cu} \mathrm{K} \alpha$ radiation $(\lambda=1.54184 \AA)$ in the $2 \theta$ range of $0.75-70.00^{\circ}$ with the $0.02^{\circ}$ step. The textural properties of these materials were investigated by means of low-temperature adsorption of nitrogen $\left(-196{ }^{\circ} \mathrm{C}\right)$ in an ASAP 2020 instrument (Micromeritics). SEM pictures were taken with a VEGA3 LM scanning electron microscope (TESCAN ORSAY HOLDING).

\section{Sample preparation}

Three food products were tested in respect of tyramine content: sauerkraut, banana, and Camembert cheese. All of them were prepared for analysis in the same way. To $6.0 \mathrm{~g}$ of homogenized sample, $8 \mathrm{~mL}$ of phosphate buffer solution $(0.1 \mathrm{M}$, $\mathrm{pH} 7$ ) was added, mixed in a vortex for $5 \mathrm{~min}$, and sonicated for $10 \mathrm{~min}$. Thereafter, the mixture was centrifuged at $+18{ }^{\circ} \mathrm{C}$ for $10 \mathrm{~min}$ at $10,000 \mathrm{rpm}$ and the supernatant was decanted and centrifuged once again at the same conditions. Finally, the extract was made up with phosphate buffer solution to a volume of $10 \mathrm{~mL}$ in a volumetric flask.

\section{Measurement procedure}

Determination of tyramine was conducted in a glass electrochemical cell of volume $20 \mathrm{~mL}$. During electrochemical measurements, cyclic voltammograms were registered and the redox peaks related to enzymatic and non-enzymatic transformations of tyramine were noticed. Both enzymatically generated anodic and cathodic peak currents, as an analytical signal, were investigated. Finally, for analytical purposes, the anodic peak current, reveled at ca. $200 \mathrm{mV}$, was selected (see section "Evaluation of analytical parameters of biosensor"). The response time of the proposed biosensor was decided to be $3 \mathrm{~min}$; however, an increasing current was recorded for $10 \mathrm{~min}$. The shorter response time was selected due to relatively high values of signal noticed after this period of time and due to the short time of the analysis procedure. The phenomenon of signal growth was noticed in our earlier studies resulting in the development of a biosensor for bisphenol A determination [34]. Because of possible matrix effects, analyses were carried out using the standard addition method.

\section{Results and discussion}

\section{Structural and textural characterization of MWCNT and CMK-3}

Both materials (MWCNT and CMK-3), chosen as the carbon matrix, show the presence of diffraction peaks at about $26^{\circ}$ and $43^{\circ}$, which can be identified as reflections from the $(002)$ and (100) planes of carbon in the graphite-like structure (Fig. 1A). Obviously, this structure has a significantly higher order of crystallinity for MWCNT. Furthermore, CMK-3 exhibits the diffraction peak at $1.1^{\circ}$ (compare inset to Fig. 1A) that can be indexed to (100) representing well-ordered hexagonal pores.

The differences in porosity of both carbon materials are clearly visible in the shape of $\mathrm{N}_{2}$ adsorption isotherms
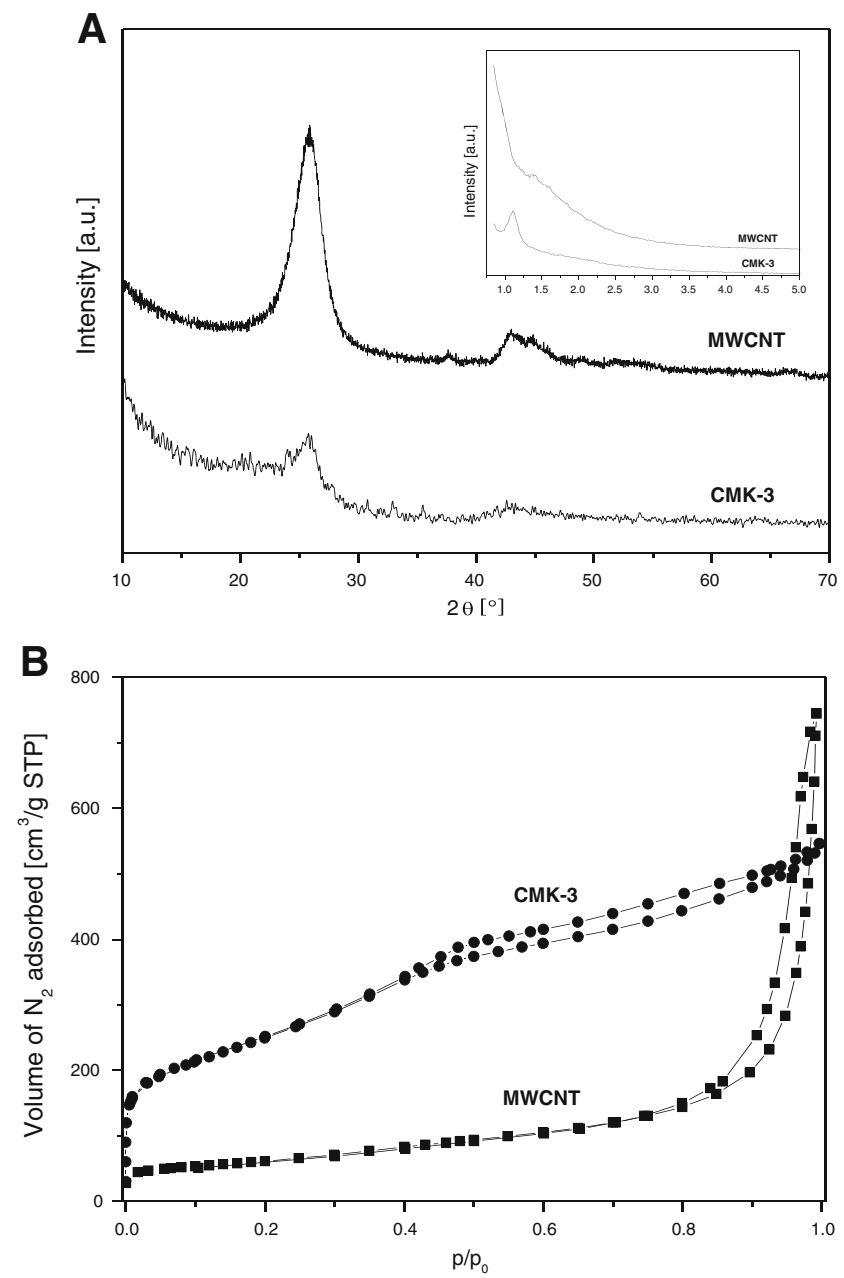

Fig. 1 X-ray diffraction patterns $(A)$ and $\mathrm{N}_{2}$ adsorption-desorption isotherms (B) for MWCNT and CMK-3 
presented in Fig. 1B. Nitrogen adsorbs on the MWCNT surface preferentially at high relative pressures suggesting the presence of interparticle cavities, which play a dominant role in the porosity of this material. The BET surface area of MWCNT $\left(S_{\mathrm{BET}}=217 \mathrm{~m}^{2} \mathrm{~g}^{-1}\right)$ is therefore rather low. On the other hand, CMK-3 possesses a huge amount of mesopores, as was tentatively suggested by XRD. Their presence is additionally manifested by the typical type IV isotherm with the $\mathrm{N}_{2}$ condensation step at $p / p_{0}=0.3-0.5$. Consequently, $S_{\mathrm{BET}}$ of CMK-3 $\left(893 \mathrm{~m}^{2} \mathrm{~g}^{-1}\right)$ is considerably higher compared to MWCNT.

\section{Preliminary voltammetric studies. Choice of carbonaceous component of matrix composite}

Preliminary electrochemical experiments were performed to verify whether using CMK-3 as the component of the TYR/
$\mathrm{TiO}_{2} / \mathrm{PDDA} / \mathrm{Nafion}$ matrix composite improves the analytical properties of the developed biosensor. For that purpose, the bioelectrode with matrix based on CMK-3 was compared with that based on multi-walled carbon nanotubes, MWCNT. The electrochemical behavior of biosensors was examined toward catechol, a model tyrosinase substrate [37]. Figure 2 shows $\mathrm{CV}$ curves recorded in $45 \mu \mathrm{M}$ catechol solution at $\mathrm{TYR} / \mathrm{TiO}_{2} /$ MWCNT/PDDA/Nafion and TYR/TiO $/$ CMK-3/PDDA/ Nafion biosensors. The comparison of the obtained $\mathrm{CV}$ and corresponding calibration curves clearly indicates that the higher response is noticed for the matrix containing CMK-3. That phenomenon could be explained by the significantly higher surface area of CMK-3, compared to MWCNT (see section "Structural and textural characterization of MWCNT and CMK-3"), and the presence of a huge amount of large-sized mesopores providing homogenous distribution of matrix components. For that reason, the $\mathrm{TiO}_{2} / \mathrm{CMK}-3 /$
Fig. $2 \mathrm{CV}$ curves recorded for $\mathrm{TYR} / \mathrm{TiO}_{2} / \mathrm{MWCNT} / \mathrm{PDDA} /$ Nafion (a) and TYR/TiO $/$ CMK3/PDDA/Nafion (b) biosensors in $45 \mu \mathrm{M}$ catechol solution (A) and corresponding calibration curves (B); scan rate, $62.5 \mathrm{mV} \mathrm{s}^{-1}$
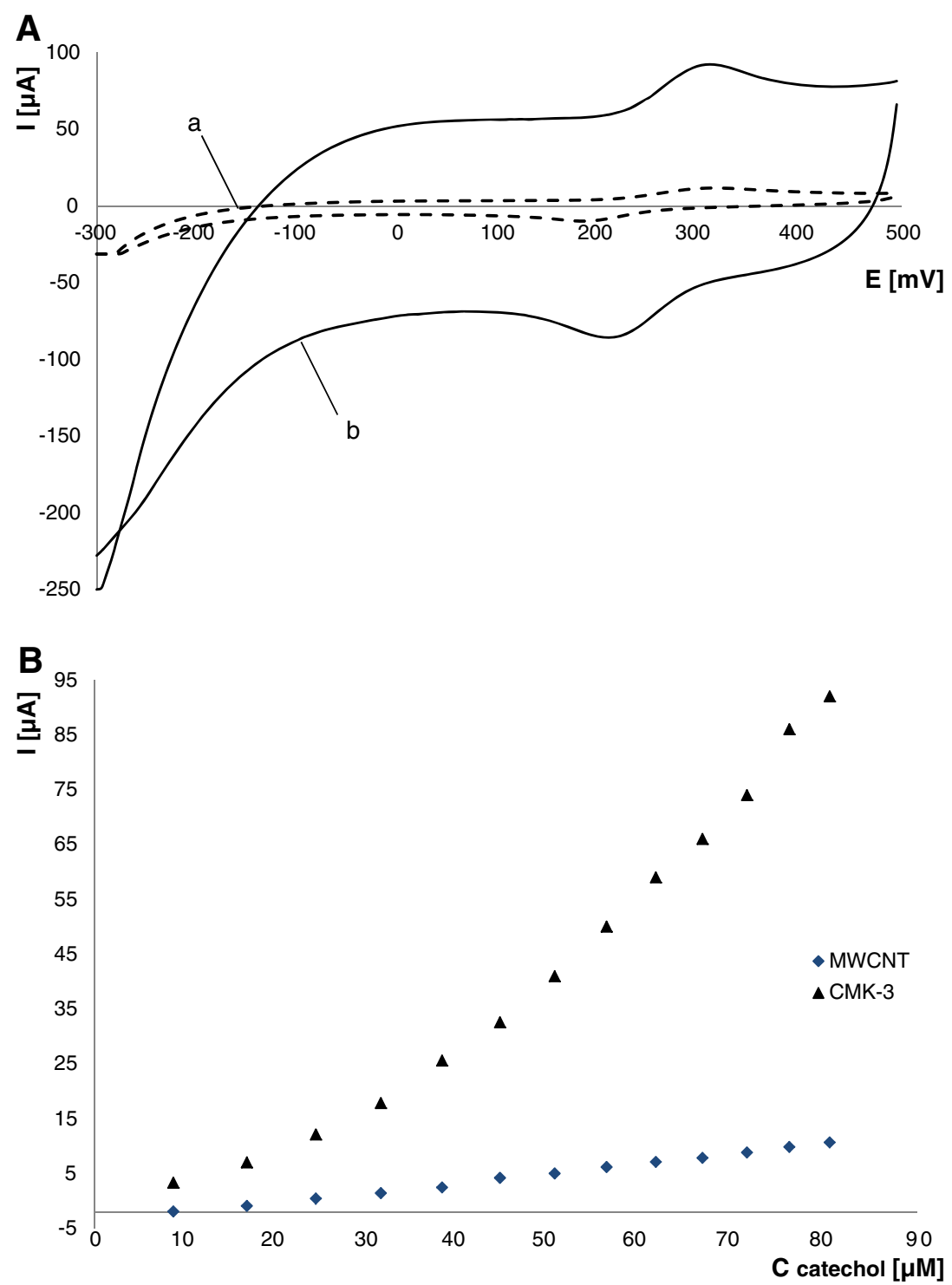
Fig. 3 SEM images of TYR/ $\mathrm{TiO}_{2} / \mathrm{CMK}-3 / \mathrm{PDDA}$ (A), TYR/ $\mathrm{TiO}_{2} / \mathrm{CMK}-3 /$ Nafion (B), and $\mathrm{TYR} / \mathrm{TiO}_{2} / \mathrm{CMK}-3 / \mathrm{PDDA} /$ Nafion $(\mathbf{C})$ composites supported on the graphite electrode surface

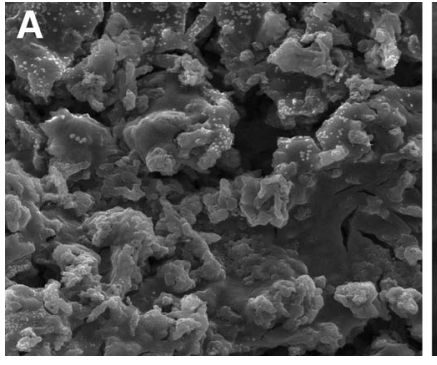

B
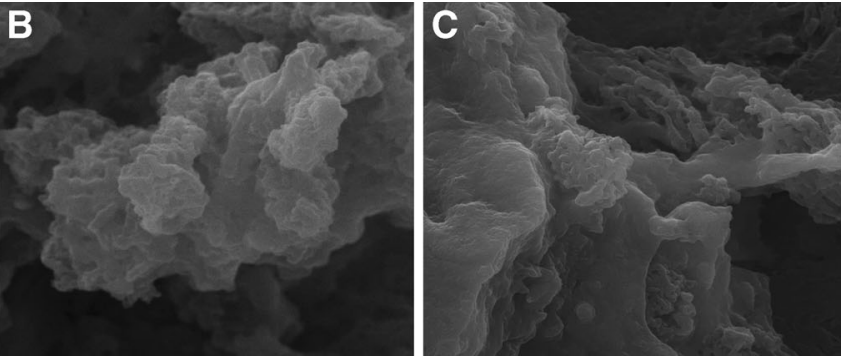

PDDA/Nafion composite was chosen as the immobilization biosensor matrix for further study.

\section{SEM characterization of $\mathrm{TiO}_{2} / \mathrm{CMK}-3 / \mathrm{PDDA} / \mathrm{Nafion}$ matrix}

The morphology of matrices containing TYR/TiO $/ \mathrm{CMK}-3$ modified with PDDA, Nafion, and both of them was characterized using scanning electron microscopy. As can be seen in Fig. 3, the structure of the TYR/TiO $/ \mathrm{CMK}-3$ matrix composite enriched with PDDA (Fig. 3A) is flatter than that with addition of Nafion (Fig. 3B). The presence of Nafion affected the tightening edge of the structure. Modification with both components, PDDA and Nafion, resulting in the $\mathrm{TYR} / \mathrm{TiO}_{2} /$ CMK-3/PDDA/Nafion matrix, increases the porosity of the composite enhancing the active surface area for enzyme immobilization. Consequently, the CMK-3/TYR/TiO $/ 2$ PDDA/ Nafion composite due to its roughness, porosity, and welldefined structure can be expected to be attractive when the construction of the electrochemical biosensor is considered.

\section{Electrochemistry of TYR/TiO $/$ /CMK-3/PDDA/Nafion biosensor}

Electrochemical studies on the developed bioelectrode were initially focused on investigation of the biosensor behavior in the solution of supporting electrolyte. Figure 4 presents cyclic voltammograms recorded in PBS obtained for the bare and $\mathrm{TiO}_{2} / \mathrm{CMK}-3 / \mathrm{PDDA} / \mathrm{Nafion}$ electrodes (Fig. 4A, curves $a$ and $b$, respectively) as well as for the $\mathrm{TYR} / \mathrm{TiO}_{2} / \mathrm{CMK}-3 /$ PDDA/Nafion biosensor (Fig. 4A, curve $c$ ). Two very broad redox peaks: anodic, stretching from ca. -110 to $150 \mathrm{mV}$, and cathodic distending from ca. -120 to $260 \mathrm{mV}$ can be revealed on the current-potential curve registered for the biosensor (Fig. 4, curve $c$ ). Since no corresponding peaks were observed for the bare and non-enzymatic $\mathrm{TiO}_{2} / \mathrm{CMK}-3 / \mathrm{PDDA} / \mathrm{Nafion}$ electrodes, the manifested pair of peaks could be attributed to the direct electron transfer (DET) between the catalytic center of tyrosinase and the electrode surface. Calculated formal potential, ca. $25 \mathrm{mV}$ vs. $\mathrm{Ag} / \mathrm{AgCl}$ (at $\mathrm{pH}$ 6), fitted in with the value of formal potential, $30 \mathrm{mV}$ vs. SCE (at $\mathrm{pH}$ 7), obtained for wired tyrosinase mechanically compressed with MWCNT [38]. Nonetheless, for tyrosinase entrapped in titania sol-gel matrix modified, among others, multi-walled carbon nanotubes, a formal potential of $250 \mathrm{mV}$ vs. $\mathrm{Ag} / \mathrm{AgCl}$ (at $\mathrm{pH}$ 6) was reported [34]. The occurrence of direct electron transfer
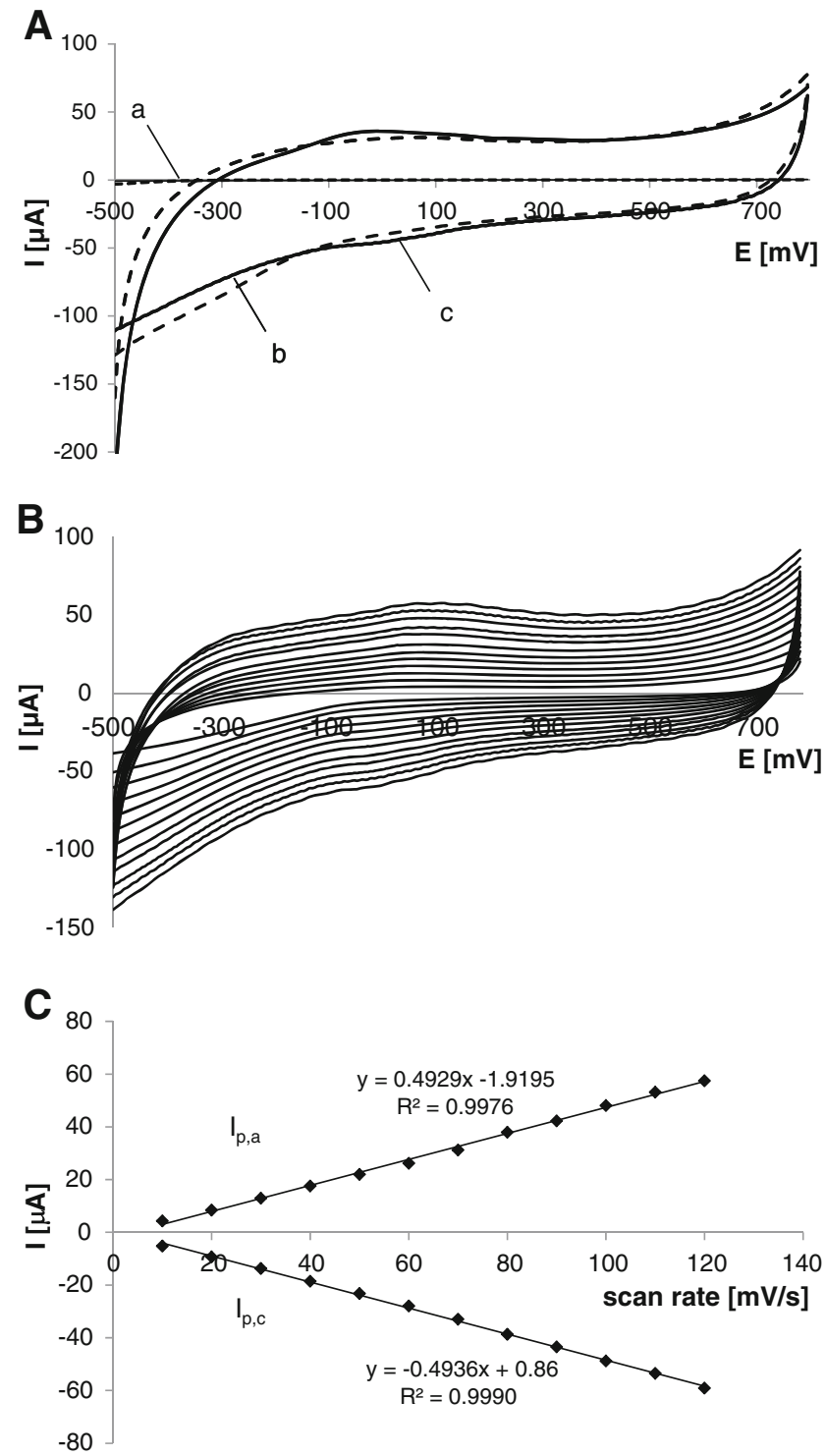

Fig. $4 \mathrm{CV}$ curves registered in solution of supporting electrolyte $(0.1 \mathrm{M}$ PBS, pH 6) at bare (a), $\mathrm{TiO}_{2} / \mathrm{CMK}-3 / \mathrm{PDDA} / \mathrm{Nafion}(\mathbf{b})$, and $\mathrm{TYR} / \mathrm{TiO}_{2} /$ CMK-3/PDDA/Nafion (c) electrodes (A); effect of scan rates (from 0 to $120 \mathrm{mV} \mathrm{s}^{-1}$ ) on cyclic voltammogram (B), and dependence of anodic $\left(I_{\mathrm{p}, \mathrm{a}}\right)$ and cathodic $\left(I_{\mathrm{p}, \mathrm{c}}\right)$ peak potential versus scan rates $\left(10-120 \mathrm{mV} \mathrm{s}^{-1}\right)$ (C) 
Fig. 5 Cyclic voltammograms registered in $0.48 \mathrm{mM}$ tyramine solution at $\mathrm{TYR} / \mathrm{TiO}_{2}(\mathbf{a}), \mathrm{TYR} /$ $\mathrm{TiO}_{2} / \mathrm{PDDA} / \mathrm{Nafion}(\mathbf{b}), \mathrm{TYR} /$ $\mathrm{TiO}_{2} / \mathrm{CMK}-3 /$ Nafion (c), and $\mathrm{TYR} / \mathrm{TiO}_{2} / \mathrm{CMK}-3 / \mathrm{PDDA} /$ Nafion biosensors (d); scan rate, $62.5 \mathrm{mV} \mathrm{s}^{-1}$

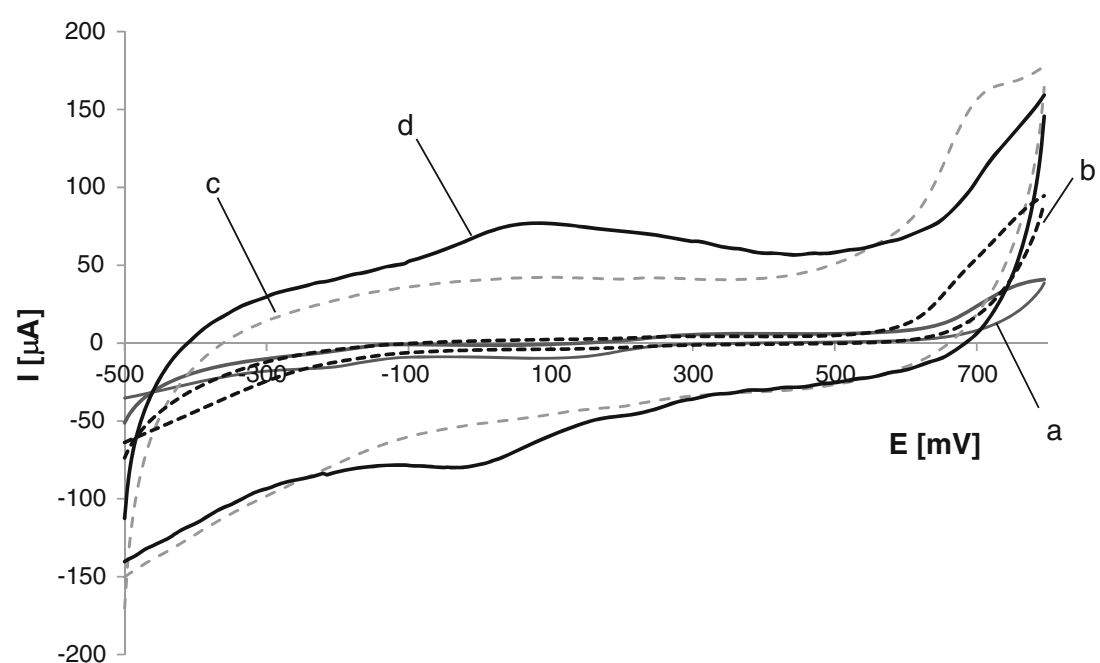

between the electrode surface and the active site of enzyme can be also observed on the CV curves registered in PBS at different scan rates, from 10 to $120 \mathrm{mV} \mathrm{s}^{-1}$ (Fig. 4B). In Fig. $4 \mathrm{C}$, it is seen that the anodic $\left(I_{\mathrm{p}, \mathrm{a}}\right)$ as well as the cathodic $\left(I_{\mathrm{p}, \mathrm{c}}\right)$ peak currents were proportional to the scan rate suggesting a surface-controlled process. Direct electron transfer of TYR was reported to appear only for few biosensors: for that based on the enzyme covalently bound to glassy carbon electrode via Woodward's reagent K [39], glassy carbon electrode modified, among others, with carbon nanotubes [34, 40, 41] and mesoporous carbon [42].

The electrochemical characterization of biosensors modified with different matrix composites was carried out in $0.48 \mathrm{mM}$ tyramine solution. Figure 5 presents $\mathrm{CV}$ curves registered for the TYR/TiO $, \mathrm{TYR} / \mathrm{TiO}_{2} / \mathrm{PDDA} / \mathrm{Nafion}, \mathrm{TYR} /$ $\mathrm{TiO}_{2} / \mathrm{CMK}-3 / \mathrm{Nafion}$, and TYR/TiO $/$ /CMK-3/PDDA/Nafion biosensors (Fig. 5, curves $a$ to $d$, respectively). It is found that biosensors based on matrices without mesoporous carbon exhibited narrow cyclic voltammograms (Fig. 5, a, b). The

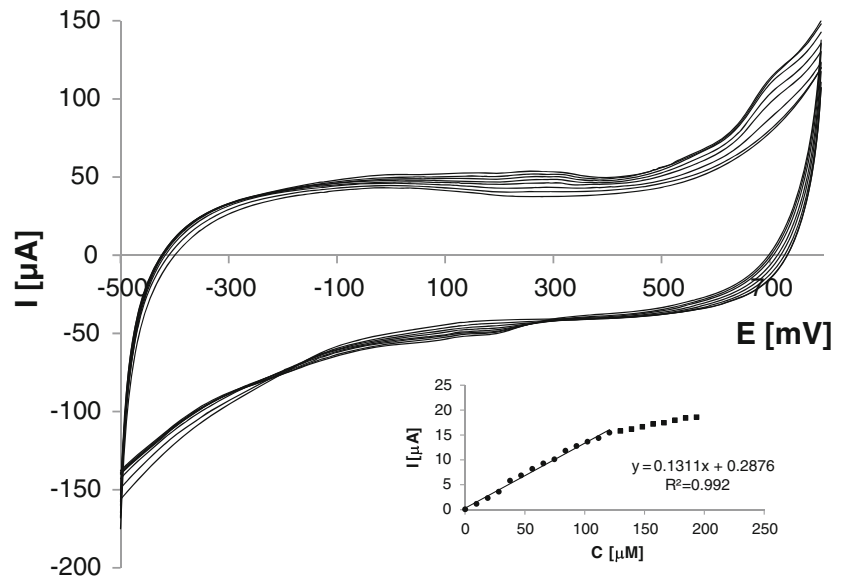

Fig. 6 Exemplary cyclic voltammograms recorded at $\mathrm{TYR} / \mathrm{TiO}_{2} / \mathrm{CMK}-$ 3/PDDA/Nafion bioelectrode in background electrolyte containing tyramine at different concentrations; inset: linear range of biosensor response; scan rate, $62.5 \mathrm{mV} \mathrm{s}^{-1}$ addition of CMK-3 into the matrix layer resulted in broadening of CV curves (Fig. 5, c, d), likely due to the increase of the effective surface area of the matrix composite. Nevertheless, a pair of broad redox peaks was noticed only for the $\mathrm{TYR} / \mathrm{TiO}_{2} /$ CMK-3/PDDA/Nafion biosensor (Fig. 5, d); no redox peaks were revealed for the other studied biosensors. The phenomenon confirmed that both PDDA and CMK-3 were necessary to develop the biosensor designed for tyramine quantification. PDDA, being positively charged, allowed entrapment of the large amount of negatively charged tyrosinase due to electrostatic attraction [43], while CMK-3 exhibiting a large surface area enhanced the amount of immobilized enzyme in its catalytically active form and ensured excellent conductivity of the biosensor matrix. The observed redox peaks could be attributed to redox processes of $o$-quinone, the product of enzymatic oxidation of tyramine (Scheme 1; see Supplementary Information). The effect of scan rates on cyclic voltammograms was investigated in the range from 10.0 to $120.0 \mathrm{mV} \mathrm{s}^{-1}$. The significant peaks' width indicated slow redox processes, both oxidation and reduction. From Fig. S1A (see Supplementary Information), it is seen that the scan rate influenced the peaks' potential position: along with the scan rate increase, the anodic peak, $E_{\mathrm{p}, \text { a }}$, moved to more positive potentials whereas the cathodic peak, $E_{\mathrm{p}, \mathrm{c}}$, shifted to less negative potentials. However, the heights of the respective anodic and cathodic current peaks seem to be equal. These observations suggest quasi-reversible redox reactions. Both anodic and cathodic peak currents exhibited a linear relationship vs. scan rate (Fig. S1B; see Supplementary Information) indicating surface-controlled electrode processes, without diffusion limitation.

\section{Evaluation of analytical parameters of biosensor}

The determination of tyramine was based on redox reactions of catalytically generated $o$-quinones taking place at an 
electrode surface (see Scheme S1; see Supplementary Information). Exemplary voltammetric responses of the developed biosensor recorded in analyte solutions of different concentrations are presented in Fig. 6. At the low tyramine concentration, the broad oxidation and reduction peaks are observed, over the potential range -150 to $400 \mathrm{mV}$. In solution with the slightly higher analyte content, the additional oxidation peak at ca. $650 \mathrm{mV}$ was detected. That peak can be attributed to direct electrochemical oxidation of the analyte, whereas the anodic peak appearing at lower potential could be the result of tyramine oxidation related to enzymatic processes. According to this approach a very broad reduction peak could be assigned to reduction of both electrochemically and enzymatically generated $o$-quinones. The analogous interpretation of $\mathrm{CV}$ curves obtained for different phenols was reported for phenol oxidase-based bioelectric tongue [44]. For analytical purposes, enzymatically generated redox peaks were examined. Both peaks were easily noticeable and their heights were increasing along with concentration of analytes (see Fig. 6). It can be discovered that oxidation peak currents were higher than respective reduction ones, which indicated better sensitivity of determination based on biosensor oxidation response. Estimation of sensitivity obtained based on reduction and oxidation peaks gave mean values of 175 and $486 \mu \mathrm{A} \mathrm{mM}^{-1} \mathrm{~cm}^{-2}$, respectively. For that reason, quantification of tyramine was based on the biosensor response corresponding to the anodic peak current centered at ca. $200 \mathrm{mV}$. Selection of the comparatively low signal potential likely permits determination of analyte without influence of other electroactive compounds that can be found in natural samples and are usually electroactive at higher potentials [45]. Biosensor response shows linear dependency on tyramine concentration from 6 to $130 \mu \mathrm{M}$ with mean sensitivity of $486 \mu \mathrm{A} \mathrm{mM}{ }^{-1} \mathrm{~cm}^{-2}\left(136 \mu \mathrm{A} \mathrm{mM}{ }^{-1}\right)$. Limit of detection
$\mathrm{LOD}=1.5 \mu \mathrm{M}$ was calculated based on the $3 s / a$ formula, where $s$ constitutes the standard deviation of signals recorded in $10 \mu \mathrm{M}$ tyramine solution $(n=10)$ and $a$ is biosensor sensitivity [46]. Repeatability and reproducibility were evaluated in $25 \mu \mathrm{M}$ tyramine solution, and they can be considered satisfying. Biosensor repeatability, estimated as standard deviation (RSD\%) of results (concentrations) obtained based on five independently received, for one bioelectrode, calibration sets, equaled $3.0 \%$. Reproducibility was obtained based on five calibration curves recorded individually for five independently prepared biosensors giving an RSD value of $3.1 \%$. For estimation of biosensor long-term stability, cyclic voltammetric response in $25 \mu \mathrm{M}$ tyramine solution was investigated. There were no significant changes of recorded current signal after 7 days of biosensor storage in PBS at $4{ }^{\circ} \mathrm{C}$, and after one additional week, the biosensor retained ca. $70 \%$ of its initial response.

Enzymatic reaction at the developed biosensor suits well the Michaelis-Menten kinetic model. The apparent Michaelis-Menten constant, $K_{\mathrm{m}}{ }^{\text {app }}$, was calculated from the electrochemical version of the Lineweaver-Burk equation [45]:

$\frac{1}{I}=\frac{1}{I_{\max }}+\frac{K_{\mathrm{m}}^{\mathrm{app}}}{I_{\max } C}$

where $I$ is the steady-state current after addition of enzyme substrate (tyramine) and $C$ constitutes tyramine concentration. The obtained value of $K_{\mathrm{m}}{ }^{\text {app }}=66.0 \mu \mathrm{M}$ is similar to the value reported for the biosensor with tyrosinase immobilized in phosphate-doped polypyrrole film, $62.65 \mu \mathrm{M}$ [16] and lower than that obtained for the screen-printed electrode with enzyme entrapped in the carboxyl-functionalized single-walled carbon nanotube composite, $88.50 \mu \mathrm{M}$ [17]. From the results,
Table 1 Comparison of analytical characteristics of electrochemical biosensors designated for tyramine determination

\begin{tabular}{|c|c|c|c|c|}
\hline Electrode & Enzyme & $\begin{array}{l}\text { Linear range } \\
{[\mu \mathrm{M}]}\end{array}$ & $\begin{array}{l}\text { LOD } \\
{[\mu \mathrm{M}]}\end{array}$ & Reference \\
\hline CPE/Nafion & Pea seedling amine oxidase & $182-7290$ & 45.2 & {$[4]$} \\
\hline $\mathrm{SPCE} / \mathrm{MnO}_{2}$ & Pea seedling amine oxidase & $1-50$ & 3.0 & {$[14]$} \\
\hline GE/Os mediator & $\begin{array}{l}\text { Monoamine oxidase } \mathrm{A} / \text { horseradish } \\
\text { peroxidase }\end{array}$ & $10-500$ & 2.0 & {$[47]$} \\
\hline $\mathrm{Pt}$ & Diamine oxidase & $1-50$ & 0.5 & {$[48]$} \\
\hline $\mathrm{Au} / \mathrm{AgNPs} / \mathrm{L}-\mathrm{Cys}$ & Tyramine oxidase & $17-250$ & 10.0 & {$[2]$} \\
\hline $\mathrm{Pt} / \mathrm{ERM}$ & Tyramine oxidase & $17-253$ & 17.5 & {$[15]$} \\
\hline $\mathrm{Pt} / \mathrm{Ppy} / \mathrm{PO}_{4}{ }^{3-}$ & Tyrosinase & $4-80$ & 0.6 & {$[16]$} \\
\hline SPCE/SWCNT-COOH & Tyrosinase & $5-180$ & 0.6 & {$[17]$} \\
\hline $\begin{array}{l}\mathrm{GE}^{-\mathrm{TiO}_{2}} / \mathrm{CMK}-3 / \text { Nafion/ } \\
\mathrm{PDDA}\end{array}$ & Tyrosinase & $6-130$ & 1.5 & $\begin{array}{l}\text { This } \\
\text { work }\end{array}$ \\
\hline
\end{tabular}

$A g N P s$ silver nanoparticles, $C P E$ carbon paste electrode, ERM epoxy resin membrane, $G E$ graphite electrode, $L$ $C y S$ L-Cysteine, $P p y$ polypyrrole, SPCE screen-printed carbon electrode, $S W C N T-C O O H$ carboxyl-functionalized single-walled carbon nanotubes 
Table 2 Quantification of tyramine in natural product samples by the proposed biosensor

\begin{tabular}{llll}
\hline Food sample & Tyramine $[\mu \mathrm{M}]$ & Average $[\mu \mathrm{M}]$ & RSD [\%] \\
\hline Camembert cheese & 28.3 & 30.0 & 7.6 \\
& 28.4 & & \\
Sauerkraut & 33.2 & & \\
& 51.3 & 45.2 & \\
& 42.4 & & \\
Fresh banana & 42.0 & & \\
& 26.7 & 25.3 & \\
& 23.8 & & 7.7 \\
Ripe banana & 25.3 & & \\
& 41.9 & 41.1 & \\
& 36.8 & & \\
\hline
\end{tabular}

it can be concluded that the TYR/TiO $/$ /CMK-3/PDDA/Nafion exhibited high biological affinity for tyramine.

The substrate specificity of the proposed biosensor was studied taking into account, as possible interferences, substances that are usually encountered in food products together with the analyte: other biogenic amines (glutathione, phenylalanine, and tryptophan), ascorbic acid, and inorganic ions $\left(\mathrm{Mg}^{2+}, \mathrm{Ca}^{2+}, \mathrm{Na}^{+}, \mathrm{Cl}^{-}, \mathrm{NO}_{3}{ }^{-}\right)$. Furthermore, three phenolic compounds, substrates of tyrosinase, usually met in banana fruit [47]: gallic, vanilla, and caffeic acids, were taken into consideration. The measurements were performed in $50 \mu \mathrm{M}$ tyramine solution. The collected results demonstrate that biogenic amines did not significantly influence the current signal up to 20-fold higher concentrations of glutathione and tryptophan, and 50-fold excess of phenylalanine. For inorganic ions, the tolerance ratio was 50 . As expected, due to reducing properties of ascorbic acid, a noticeable increase of anodic and a decrease of cathodic peak currents were revealed at its concentration above $0.5 \mathrm{mM}$. A study on the interference effect of tyrosinase substrates showed that gallic acid did not change the analytical signal up to fivefold excess, while for vanilla and caffeic acids at a concentration of $50 \mu \mathrm{M}$, the current increase was revealed. Schematic presentation of the influence of interferences on analytical signal recorded in $50 \mu \mathrm{M}$ tyramine solution is shown in Fig. S2 (see Supplementary Information). To evaluate the type of matrix effects and to determine accurate results employing integrated calibration [48] or generalized calibration strategy [49] could be suggested.

The performance of the proposed $\mathrm{TYR} / \mathrm{TiO}_{2} / \mathrm{CMK}-3 /$ PDDA/Nafion biosensor was compared with that of other biosensors designated for tyramine quantification. Taking into consideration the limit of detection, it can be stated (Table 1) that the developed biosensor exhibited lower LOD in comparison with biosensors based on tyramine oxidase $[2,15]$, monoamine oxidase [50], and pea seedling amine oxidase [4, 14] but higher than tyrosinase-based biosensors $[16,17]$ and the diamine oxidase-based bioelectrode [51]. Linear range is comparable to or narrower than ranges reported for other biosensors. Compared with other tyrosinase-based biosensors, the proposed biosensor exhibited high sensitivity toward the analyte, ca. $30 \%$ higher than reported for biosensor with phosphatedoped polypyrrole matrix [16] but lower than that reported for a screen-printed electrode with enzyme entrapped in the carboxyl-functionalized single-walled carbon nanotube composite [17]. The limit of detection of the proposed biosensor, $1.5 \mu \mathrm{M}$, was higher than that described for other tyrosinasebased biosensors, $0.6 \mu \mathrm{M}[16,17]$. Nonetheless, it is worth mentioning that from a toxicological point of view, only the consumption of a large amount of tyramine and other biogenic amines can be dangerous for human health. There is no legislation in the EU to limit the content of biogenic amines in food except from histamine in fish products $\left(400 \mathrm{mg} \mathrm{kg}^{-1}\right)$ [52]. Therefore, it seems that the developed biosensor exhibited a low enough LOD, $1.5 \mu \mathrm{M}\left(0.21 \mathrm{mg} \mathrm{L}^{-1}\right)$, to be useful for the determination of high tyramine concentration in food products. In support of this statement, the example of studies on in vitro cytotoxic effect of tyramine and other biogenic amines, at concentrations of $0.7 \mathrm{mM}$ and higher, can be given [52].

On the other hand, it can be noticed that preparation of Tyr/ SWCNT-COOH/SPE proposed by Apatrei et al. [17] requires use of vapor of glutaraldehyde, a very harmful reagent that can not only contribute to asthma symptoms, severe skin burns, and allergic skin reaction but is also very toxic to aquatic life with long-lasting effects. Construction of the proposed Tyr/ $\mathrm{TiO}_{2} / \mathrm{CMK}-3 / \mathrm{PDDA} /$ Nafion biosensor also involves an unsafe reagent, Nafion, but it is used in solution and it is significantly less harmful than vapor of glutaraldehyde. Taking into account the roles of green chemistry and green analytical
Table 3 Analytical recovery of added tyramine in the food samples

\begin{tabular}{llllll}
\hline Real sample & $\begin{array}{l}\text { Tyramine determined } \\
{[\mu \mathrm{M}]}\end{array}$ & $\begin{array}{l}\text { Tyramine spiked } \\
{[\mu \mathrm{M}]}\end{array}$ & $\begin{array}{l}\text { Tyramine detected } \\
{[\mu \mathrm{M}]}\end{array}$ & $\begin{array}{l}\text { Recovery } \\
{[\%]}\end{array}$ & $\begin{array}{l}\text { RSD } \\
{[\%]}\end{array}$ \\
\hline $\begin{array}{l}\text { Camembert } \\
\text { cheese }\end{array}$ & 30.0 & 24.3 & 52.4 & 92.2 & 7.3 \\
$\begin{array}{l}\text { Sauerkraut } \\
\text { Banana }\end{array}$ & 45.2 & 24.3 & 67.8 & 93.0 & 4.5 \\
\hline
\end{tabular}


chemistry [53], the presented $\mathrm{Tyr} / \mathrm{TiO}_{2} / \mathrm{CMK}-3 / \mathrm{PDDA} /$ Nafion biosensor should be considered as a greener device.

\section{Verification of biosensor functioning. Natural sample analyses}

The developed biosensor was examined for its applicability in complex natural matrices, specifically in natural food products as Camembert cheese, sauerkraut, and banana. The volume of $0.5 \mathrm{~mL}$ of Camembert cheese and sauerkraut extracts or $1 \mathrm{~mL}$ of banana extract (see section "Sample preparation") was taken for measurements. The analyses were performed using the standard addition method, based on six standard additions; each sample was analyzed three times. From Table 2, it is seen that the precision of the method can be regarded as satisfactory for natural samples, because the RSD value did not exceed $10 \%$. It was found that Camembert cheese contained $143.8 \mathrm{mg} \mathrm{kg}^{-1}$ whereas exemplary for Pecorino Romano cheese value of $116.7 \mathrm{mg} \mathrm{kg}^{-1}$ was reported [54]. The tyramine content in the sauerkraut sample was obtained to be $217.2 \mathrm{mg} \mathrm{kg}^{-1}$ compared with the value of $264.5 \mathrm{mg} \mathrm{kg}^{-1}$ detected by Apatrei [16]. The amount of tyramine in the fresh banana sample was calculated to be $121.2 \mathrm{mg} \mathrm{kg}^{-1}$.

It is worth emphasizing that the tyramine content in food products varies and depends on such processes as ripening, fermentation, and degradation. In order to verify the usefulness of our biosensor in monitoring of ripening, part of the banana sample was left in the laboratory at room temperature for 4 days and after that time analyzed again. According to expectation, the tyramine content increased to $197.4 \mathrm{mg} \mathrm{kg}^{-1}$ proving that the proposed bioelectrode can be useful in screening of natural processes occurring in food.

To evaluate the efficiency of the proposed method, recovery studies were carried out. Examined food samples were spiked with $24.3 \mu \mathrm{M}$ tyramine. From Table 3, it is seen that the proposed approach gave reliable results, as values 92.2, 93.0, and $102.1 \%$ of recovery for Camembert cheese, sauerkraut, and banana samples, respectively, were obtained, with a mean recovery value of $95.8 \%$.

\section{Conclusions}

A voltammetric biosensor based on tyrosinase immobilized in the $\mathrm{TiO}_{2} / \mathrm{CMK}-3 / \mathrm{PDDA} / \mathrm{Nafion}$ composite for the determination of tyramine in food products was proposed. The performed experiments proved that the mesoporous carbon material was an essential component of the matrix composite influencing the electrochemical biosensor response. The developed matrix composite ensured an adequate medium for entrapment of a large amount of tyrosinase in its catalytically active form that could be concluded from the phenomenon of direct electron transfer between the catalytic center of the enzyme and the electrode surface. The resulting biosensor presents good analytical characteristics in the quantification of tyramine, especially concerning high sensitivity and low value of LOD.

The present biosensor can operate as an amperometric device after optimization of the working electrode potential, both in batch and flow (e.g., FIA) modes. The optimal speed of steering should be found for batch conditions whereas appropriate volumes and flow rates of the sample and standard additions should be optimized for the FIA system.

It was demonstrated that without a complicated sample pretreatment and sophisticated apparatus, the biosensor can constitute an alternative method not only to determine tyramine in food but also to monitor food quality. Moreover, the developed biosensor matrix has the capability to be involved in the construction of other bioelectrodes.

\section{Compliance with ethical standards}

Conflict of interest The authors declare that they have no competing interests.

Ethical approval This article does not contain any studies with human participants or animals performed by any of the authors.

Open Access This article is distributed under the terms of the Creative Commons Attribution 4.0 International License (http:// creativecommons.org/licenses/by/4.0/), which permits unrestricted use, distribution, and reproduction in any medium, provided you give appropriate credit to the original author(s) and the source, provide a link to the Creative Commons license, and indicate if changes were made.

\section{References}

1. Baghayeri M, Namadchianba M. Fabrication of a nanostructured luteolin biosensor for simultaneous determination of levodopa in the presence of acetaminophen and tyramine: application to the analysis of some real samples. Electrochim Acta. 2013;108:22-31.

2. Batra B, Lata S, Devi R, Yadav S, Pundir CS. Fabrication of an amperometric tyramine biosensor based on immobilization of tyramine oxidase on AgNPs/L-Cys-modified Au electrode. J Solid State Electrochem. 2012;16:3869-76.

3. Henao-Escobar W, Domínguez-Renedo O, Alonso-Lomillo MA, Arcos-Martínez MJ. Resolution of quaternary mixtures of cadaverine, histamine, putrescine and tyramine by the square wave voltammetry and partial least squares method. Talanta. 2015;143:97100 .

4. Telsnig D, Kassarnig V, Zapf C, Leitinger G, Kalcher K, Ortner A. Characterization of an amperometric biosensor for the determination of biogenic amines in flow injection analysis. Int J Electrochem Sci. 2012;7:10476-86.

5. Hanington E. Preliminary report on tyramine headache. Br Med J. 1967;2:550-1.

6. Yamamoto S, Wakabayashi S, Makita M. Gas-liquid chromatographic determination of tyramine in fermented food products. J Agric Food Chem. 1980;28:790-3. 
7. Wang YQ, Ye DQ, Zhu BQ, Wu GF, Duan CQ. Rapid HPLC analysis of amino acids and biogenic amines in wines during fermentation and evaluation of matrix effect. Food Chem. 2014;163: 6-15.

8. Piasta AM, Jastrzębska A, Krzemiński MP, Muzioł TM, Szłyk E. New procedure of selected biogenic amines determination in wine samples by HPLC. Anal Chim Acta. 2014;834:58-66.

9. Önal A, Tekkeli SEK, Önal C. A review of the liquid chromatographic methods for the determination of biogenic amines in foods. Food Chem. 2013;138:509-15.

10. Todoroki K, Ishii Y, Miyauchi C, Kitagawa S, Min JZ, Inoue K, et al. Simple and sensitive analysis of histamine and tyramine in Japanese soy sauces and their intermediates using the stable isotope dilution HILIC-MS/MS method. J Agric Food Chem. 2014;62: 6206-11

11. Gong X, Qi N, Wang X, Lin L, Li J. Ultra-performance convergence chromatography (UPC2) method for the analysis of biogenic amines in fermented foods. Food Chem. 2014;162:172-5.

12. Daniel D, dos Santos VB, Vidal DTR, do Lago CL. Determination of biogenic amines in beer and wine by capillary electrophoresistandem mass spectrometry. J Chromatogr A. 2015;1416:121-8.

13. An D, Chen Z, Zheng J, Chen S, Wang L, Huang Z, et al. Determination of biogenic amines in oysters by capillary electrophoresis coupled with electrochemiluminescence. Food Chem. 2015;168:1-6

14. Telsnig D, Kalcher K, Leitner A, Ortner A. Design of an amperometric biosensor for the determination of biogenic amines using screen printed carbon working electrodes. Electroanalysis. 2013;25:47-50.

15. Lata S, Yadav S, Bhardwaj R, Pundir CS. Amperometric determination of tyramine in sauce and beer by epoxy resin biocomposite membrane bound tyramine oxidase. Sens \& Instrumen Food Qual. 2011;5:104-10.

16. Apetrei IM, Apetrei C. Amperometric biosensor based on polypyrrole and tyrosinase for the detection of tyramine in food samples. Sensors Actuators B. 2013;178:40-6.

17. Apetrei IM, Apetrei C. The biocomposite screen-printed biosensor based on immobilization of tyrosinase onto the carboxyl functionalised carbon nanotube for assaying tyramine in fish products. J Food Eng. 2015;149:1-8.

18. Yue Y, Hu GZ, Zheng MB, Guo Y, Cao JM, Shao SJ. A mesoporous carbon nanofiber-modified pyrolytic graphite electrode used for the simultaneous determination of dopamine, uric acid, and ascorbic acid. Carbon. 2012;50:107-14.

19. Bathinapatla A, Kanchi S, Singh P, Sabela MI, Bisetty K. An ultrasensitive performance enhanced novel cytochrome $\mathrm{c}$ biosensor for the detection of rebaudioside A. Biosens Bioelectron. 2016;77:11623.

20. Ye C, Zhong X, Chai Y, Yuan R. Sensing glucose based on its affinity for concanavalin A on a glassy carbon electrode modified with a C60 fullerene nanocomposite. Microchim Acta. 2015;182: 2215-21.

21. Ryoo R, Joo SH, Jun S. Synthesis of highly ordered carbon molecular sieves via template-mediated structural transformation. J Phys Chem. 1999;37:7743-6.

22. Ryoo R, Joo SH. Nanostructured carbon materials synthesized from mesoporous silica crystals by replication. Stud Surf Sci Catal. 2004;148:241-60.

23. Walcarius A. Electrocatalysis, sensors and biosensors in analytical chemistry based on ordered mesoporous and macroporous carbonmodified electrodes. Trends Anal Chem. 2012;38:79-97.

24. Guo Z, Li S, Liu XM, Gao YP, Zhang WW, Ding XP. Mesoporous carbon-polyaniline electrode: characterization and application to determination of copper and lead by anodic stripping voltammetry. Mater Chem Phys. 2011;128:238-42.
25. Song S, Gao Q, Xia K, Gao L. Selective determination of dopamine in the presence of ascorbic acid at porous-carbon-modified glassy carbon electrodes. Electroanalysis (NY). 2008;20:1159-66.

26. Bo X, Bai J, Yang L, Guo L. The nanocomposite of PtPd nanoparticles/onion-like mesoporous carbon vesicle for nonenzymatic amperometric sensing of glucose. Sensors Actuators B. 2011:157:662-8.

27. Ndamanisha JC, Hou Y, Bai J, Guo L. Effects of ferrocene derivative on the physico-chemical and electrocatalytic properties of ordered mesoporous carbon. Electrochim Acta. 2009;54:3935-42.

28. Fang J, Qi B, Yang L, Guo L. Ordered mesoporous carbon functionalized with poly-azure B for electrocatalytic application. J Electroanal Chem. 2010;643:52-7.

29. Zang J, Guo CX, Hu F, Yu L, Li CM. Electrochemical detection of ultratrace nitroaromatic explosives using ordered mesoporous carbon. Anal Chim Acta. 2011;683:187-91.

30. Ma Y, Hu G, Shao S, Guo Y. An amperometric sensor for uric acid based on ordered mesoporous carbon-modified pyrolytic graphite electrode. Chem Pap. 2009;63:641-5.

31. Feng JJ, Xu JJ, Chen HY. Direct electron transfer and electrocatalysis of hemoglobin adsorbed on mesoporous carbon through layer-by-layer assembly. Biosens Bioelectron. 2007;22: 1618-24.

32. Yang X, Feng B, Yang P, Ding Y, Chen Y, Fei J. Electrochemical determination of toxic ractopamine at an ordered mesoporous carbon modified electrode. Food Chem. 2014;145:619-24.

33. Wang H, Qi B, Lu B, Bo X, Guo L. Comparative study on the electrocatalytic activities of ordered mesoporous carbons and graphene. Electrochim Acta. 2011;56:3042-8.

34. Kochana J, Wapiennik K, Kozak J, Knihnicki P, Pollap A, Woźniakiewicz M, et al. Tyrosinase-based biosensor for determination of bisphenol A in a flow-batch system. Talanta. 2015;144: 163-70.

35. Niebrzydowska P, Janus R, Kuśtrowski P, Jarczewski S, SilvestreAlbero AM, Rodriguez-Reinoso F. A simplified route to the synthesis of CMK-3 replica based on precipitation polycondensation of furfuryl alcohol in SBA-15 pore system. Carbon. 2013;64:252-61.

36. Adamski J, Kochana J. Meldola's Blue-doped titania sol-gel sensor for NADH determination. Cent Eur J Chem. 2011;9:185-91.

37. Solomon EI, Sundaram UM, Machonkin TE. Multicopper oxidases and oxygenases. Chem Rev. 1996;96:2563-605.

38. Reuillard B, Le Goff A, Agnes C, Zebda A, Holzinger M, Cosnier $\mathrm{S}$. Direct electron transfer between tyrosinase and multi-walled carbon nanotubes for bioelectrocatalytic oxygen reduction. Electrochem Commun. 2012;20:19-22.

39. Faridnouri H, Ghourchian H, Hashemnia S. Direct electron transfer enhancement of covalently bound tyrosinase to glassy carbon via Woodward's reagent K. Bioelectrochemistry. 2011;82:1-9.

40. Ballesteros-Gómez A, Rubio S, Pérez-Bendito D. Analytical methods for the determination of bisphenol A in food. J Chromatogr A. 2009;1216:449-69.

41. Mohammadi A, Moghaddam AB, Hosseini S, Kazemzad M, Dinarvand R. A norepinephrine biosensor based on a glassy carbon electrode modified with carbon nanotubes. Anal Methods. 2011;3: 2406-11.

42. Wang X, Lu X, Wu L, Chen J. Direct electrochemical tyrosinase biosensor based on mesoporous carbon and $\mathrm{Co}_{3} \mathrm{O}_{4}$ nanorods for the rapid detection of phenolic pollutants. ChemElectroChem. 2014;1: 808-16.

43. Cheng Y, Liu Y, Huang J, Li K, Xian Y, Zhang W, et al. Amperometric tyrosinase biosensor based on $\mathrm{F}_{\mathrm{e}} \mathrm{O}_{4}$ nanoparticles-coated carbon nanotubes nanocomposite for rapid detection of coliforms. Electrochim Acta. 2009;54:2588-94.

44. Medina-Plaza C, de Saja JA, Rodriguez-Mendez MI. Bioelectronic tongue based on lipidic nanostructured layers containing phenol 
oxidases and lutetium bisphthalocyanine for the analysis of grapes. Biosens Bioelectron. 2014;57:276-83.

45. Apetrei C, Rodriguez-Mendez MI, De Saja JA. Amperometric tyrosinase based biosensor using an electropolymerized phosphatedoped polypyrrole film as an immobilization support. Application for detection of phenolic compounds. Electrochim Acta. 2011;56: 8919-25.

46. Kochana J, Kozak J, Skrobisz A, Woźniakiewicz M. Tyrosinase biosensor for benzoic acid inhibition-based determination with the use of a flow-batch monosegmented sequential injection system. Talanta. 2012;96:147-52.

47. Ewané CA, Lepoivre P, de Bellaire LL, Lassois L. Involvement of phenolic compounds in the susceptibility of bananas to crown rot. A review. Biotechnol Agron Soc Environ. 2012;1:393-404.

48. Kościelniak P, Akcin G, Herman M, Kozak J, Wieczorek M. A new approach to the integrated calibration in flow injection analysis. Ann Chim. 2003;903:1045-58.

49. Kościelniak P, Wieczorek M, Kozak J, Herman M. Generalized calibration strategy in analytical chemistry. Anal Lett. 2011;44: 411-30.
50. Bóka B, Adányi N, Virág D, Sebela M, Kiss A. Spoilage detection with biogenic amine biosensors, comparison of different enzyme electrodes. Electroanalysis. 2012;24:181-9.

51. Draisci R, Volpe G, Lucentini L, Cecilia A, Federico R, Palleschi G. Determination of biogenic amines with an electrochemical biosensor and its application to salted anchovies. Food Chem. 1998;2: 225-32.

52. Linares D, Del Rio B, Redruello B, Ladero V, Martin MC, Fernandez M, et al. Comparative analysis of the in vitro cytotoxicity of the dietary biogenic amines tyramine and histamine. Food Chem. 2016;197:658-63.

53. Gałuszka A, Migaszewski Z, Namieśnik J. The 12 principles of green analytical chemistry and the SIGNIFICANCE mnemonic of green analytical practices. TrAC Trends Anal Chem. 2013;50:7884.

54. Spizzirri UG, Restuccia D, Curcio M, Parasi OI, Iemma F, Picci N. Determination of biogenic amines in different cheese samples by LC with evaporative light scattering detector. J Food Compos Anal. 2013;29:43-51. 